\title{
Effect of quercetin-conjugated superparamagnetic iron oxide nanoparticles on diabetes-induced learning and memory impairment in rats
}

This article was published in the following Dove Press journal: International Journal of Nanomedicine

\author{
Shiva Ebrahimpour' \\ Abolghasem Esmaeili' \\ Siamak Beheshti \\ 'Cell, Molecular Biology and \\ Biochemistry Division, Department of \\ Biology, Faculty of Sciences, University \\ of Isfahan, Isfahan, Iran; ${ }^{2}$ Division \\ of Animal Sciences, Department of \\ Biology, Faculty of Sciences, University \\ of Isfahan, Isfahan, Iran
}

Background: Diabetes mellitus plays a causative role in cognitive decline. Newly, neuroprotective effects of flavonoids have been widely investigated in neurodegenerative diseases. Quercetin (QC) is a phyto-derived bioactive flavone with numerous beneficial activities. However, its limited permeability to cross the blood-brain barrier, low oral bioavailability, poor aqueous solubility, and rapid gastrointestinal digestion lead to the administration of high dose of QC in clinical application.

Materials and methods: In order to overcome these limitations, we conjugated QC with superparamagnetic iron oxide nanoparticles (QCSPIONs) and supplemented streptozotocininduced diabetic rats with it to improve diabetes-related memory impairment. In this regard, 40 rats were distributed into five groups with eight animals: control, diabetes, and diabetes treated with SPIONs, QC, and QCSPIONs. All treatments (at the dose of $25 \mathrm{mg} / \mathrm{kg}$ ) were dissolved in deionized water and gavaged for 35 consecutive days.

Results: At the end of the study, QCSPIONs possessed significantly better efficacy than free $\mathrm{QC}$ on the improvement of memory performance. In the Morris water maze test, QCSPIONs compared to free QC reduced much better the escape latency over training trials $(P<0.01)$ and increased the time spent in the target quadrant in probe trial $(P<0.001)$. In the passive avoidance test, it increased step-through latency $(P<0.05)$ and reduced the time spent in the dark compartment $(P<0.01)$. In addition, both free QC and QCSPIONs were able to prevent the changes in body weight and decrease blood glucose levels in diabetic rats $(P<0.05)$.

Conclusion: Overall, according to these results, we conclude that QC in the conjugated state with lower dose offers significantly higher potency in ameliorating diabetes-related memory impairment. Thus, this study offers an effective combined therapy for improving learning and memory.

Keywords: diabetes mellitus, cognitive decline, conjugated quercetin, nanoparticles

\section{Introduction}

Diabetes mellitus (DM) is the most common metabolic disorder in which high levels of plasma glucose are detected due to inadequate insulin secretion by $\beta$-cell (type $1 \mathrm{DM}$ ) or body resistance to insulin action (type $2 \mathrm{DM}$ ). ${ }^{1}$ The association between diabetes and dementia was first observed in 1999. This study reported that diabetes could double the risk of dementia and Alzheimer's disease (AD). ${ }^{2}$ Further studies also revealed that elevated plasma glucose level is a major pathological link between uncontrolled diabetes and development of dementia. ${ }^{3-5}$ It has been shown that cognitive inefficiency associated with diabetes is a result of structural changes in the central nervous system (CNS), reduction in the hippocampal size, brain tissue atrophy, alteration in the electrical characteristics of nerve tissue, reduction of hippocampal neurogenesis and impaired proliferation, and differentiation of neural progenitor cells into neurons. ${ }^{6-9}$
Correspondence: Abolghasem Esmaeili Cell, Molecular Biology and Biochemistry Division, Department of Biology, Faculty of Sciences, University of Isfahan, Hezar Jarib Street, Isfahan, Iran

Tel +983137932490

$\mathrm{Fax}+983137932456$

Email aesmaeili@sci.ui.ac.ir 
Generally, chronic hyperglycemia triggers a non-enzymatic reaction between blood glucose and free amino groups of proteins, lipids, and nucleic acids, thereby increasing advanced glycation end products (AGEs) and their receptors on the surface of neurons and glial cells. ${ }^{10}$ AGEs have been proposed as a causal link between diabetes and AD by several mechanisms. ${ }^{11}$ 1) AGEs stimulate activation of GSK3 $\beta$, one of the kinases that phosphorylate tau, through AGEs/RAGE/ GSK3 $\beta$ pathway that leads to tau hyperphosphorylation and thereby accumulation of neurofibrillary tangles in the brain, which is an important hallmark of AD. ${ }^{12}$ 2) AGEs lead to $\mathrm{NF}-\kappa \mathrm{B}$ activation through $\mathrm{AGEs} / \mathrm{RAGE} / \mathrm{NF}-\kappa \mathrm{B}$ pathway that results in the upregulation of BACE1 and $A \beta P P$ expression. Elevated A $\beta$ PP and BACE1 expression ultimately leads to enhanced amyloidogenic A $\beta$ PP processing and amyloid beta (A $\beta$ ) production, another important mark of AD. ${ }^{13-15} 3$ ) AGE accumulation might affect the O-GlcNAcylation process that triggers the production and accumulation of $A \beta$ and abnormal hyperphosphorylation of tau. ${ }^{16} 4$ ) AGEs also produce reactive oxygen species (ROS) in brain tissue by binding to their receptors. Oxidative stress may increase $A \beta$ pathology, via stimulating APP gene expression or modifying its processing via modulating $\gamma$ - and $\beta$-secretase. ${ }^{16,17}$

Quercetin (QC; 3,3',4',5,7-pentahydroxyflavone) is one of the most important natural flavonoid found in many fruits, seeds, vegetables, and oil. It has the potency to scavenge ROS and modulate neuroinflammation with unremarkable toxicological profile. ${ }^{18}$ These qualities are considered favorable for improvement in various types of cancers, cardiovascular disease, viral infections, gastrointestinal diseases, obesity, cataracts, inflammatory diseases, DM, and a number of neurological diseases. ${ }^{19}$ It has been shown that QC treatment can enhance cognitive impairment in the diabetic rats, which may have the potential for treating neuropathy in diabetic patients. ${ }^{20,21}$ In spite of beneficial properties of QC, some in vivo studies have shown that its concentration is very low to pass the blood-brain barrier (BBB) due to poor stability, solubility, distribution, and bioavailability in the brain. ${ }^{22}$ Therefore, different QC formulation strategies have been offered to reduce the dose and ameliorate the efficiency of this compound. Kim et al demonstrated that solubility, stability, and cell permeability of QC amino acid conjugates such as QC glutamic acid conjugate is better than free QC.$^{23}$ Also, Kumari et al used QC encapsulated with poly-D,L-lactide nanoparticles (NPs) in order to the improvement of its poor aqueous solubility and stability. ${ }^{24}$ Recently, the superparamagnetic iron oxide nanoparticles (SPIONs) with unique properties including high surface to mass ratio, high magnetization, colloidal stability, cellular absorption, and bio-distribution become the most effective parameters for carrying drugs, proteins, and probes. ${ }^{25}$ This NP because of these advantages has been used as a targeted drug delivery system to carry QC for chemotherapy applications. ${ }^{25,26}$ However, there are no reports concerning the application of SPIONs as a drug delivery system to carry QC against diabetes-related memory impairment. Therefore, the current study was designed to investigate the effect of QC conjugated with dextran-coated SPIONs (QCSPIONs) to the improvement of memory dysfunction in multiple low-dose streptozotocin (STZ)-induced diabetic rats and compare its effects with free QC.

\section{Materials and methods Chemicals}

QC (>95\% purity, Q4951, molecular formula C15H10O7, and molecular weight: $302.238 \mathrm{~g} / \mathrm{mol})$, STZ, dextran, dimethyl sulfoxide, N-hydroxysuccinimide (NHS), 1-ethyl3-(3-dimethylaminopropyl) carbodiimide, and ammonia $\left(\mathrm{NH}_{3}\right)$ were purchased from Sigma-Aldrich Co. (St Louis, MO, USA). Iron (III) chloride $\left(\mathrm{FeCl}_{3}\right)$ and iron (II) chloride $\left(\mathrm{FeCl}_{2}\right)$ were obtained from EMD Millipore (Billerica, MA, USA). PBS and other chemicals used in this experiment were purchased from Cinnagene (Tehran, Iran).

\section{Synthesis of quercetin conjugated $\mathrm{Fe}_{3} \mathrm{O}_{4}$ NPs (QCSPIONs)}

The protocol of QCSPION preparation was in accordance with a previous literature, ${ }^{25}$ but with certain modifications. Chemical coprecipitation method was used to synthesize dextran-coated $\mathrm{Fe}_{3} \mathrm{O}_{4}$ NPs. Briefly, a mixture containing $\mathrm{FeCl}_{3}$ anhydrous, $\mathrm{FeCl}_{2}$, and dextran dissolved in deionized (DI) water was put into a three-neck flask equipped with a mechanical stirrer. Then ammonia solution was dropped into the mixture until the $\mathrm{pH}$ of the solution reached 9. This solution was kept at $90^{\circ} \mathrm{C}$ for 2 hours with fixed stirring; then the resultant precipitate was collected with the assistance of a powerful external magnet. The supernatant was washed several times with DI water and ethanol and was dried in an oven at $70^{\circ} \mathrm{C}$ overnight.

In order to prepare QC-conjugated magnetite NPs, QC was added to dextran-coated $\mathrm{Fe}_{3} \mathrm{O}_{4} \mathrm{NPs}$. Fourier transform infrared (FTIR) spectroscopy was recorded on a Jasco 6300 spectrophotometer (JASCO, Baltimore-Washington, USA) in transmission mode with $\mathrm{KBr}$ pellets, operating from the wave numbers between 400 and 4,000 $\mathrm{cm}^{-1}$. X-ray diffraction (XRD) patterns of magnetite NPs were collected by using $\mathrm{Cu} \mathrm{Kal}(\mathrm{k}=1.54056 \AA)$ radiation on a PANalytical 
X'PERT PRO powder X-ray diffractometer at the room temperature. The morphological features were obtained on a Hitachi S-4700 field emission scanning electron microscope, equipped with an energy dispersive X-ray analysis detector. The molecular weight of $\mathrm{Fe}_{3} \mathrm{O}_{4} \mathrm{NPs}$ is $231.533 \mathrm{~g} / \mathrm{mol}$.

\section{Animals}

Male Wistar rats (40 animals weighing 200-230 g) purchased from the Royan Institute (Isfahan, Iran) were used in this experiment. The rats were maintained for 2 months in an air-conditioned room with constant temperature environment $\left(25^{\circ} \mathrm{C} \pm 2^{\circ} \mathrm{C}\right.$ and a humidity of $\left.40 \%-50 \%\right)$ and a 12-hour light/ dark cycle with free access to food and water. All procedures were conducted in accordance with the guidelines for the care and use of laboratory animals (USA National Institute of Health Publication No 80-23, revised 1996) and were reviewed and approved by the animal ethics committee of the University of Isfahan.

\section{Experimental induction of diabetes}

Before the initiation of the study, all the rats were acclimatized for 10 days (four rats per cage). Type 1 diabetes was induced through intraperitoneal injections of $20 \mathrm{mg} / \mathrm{kg} \mathrm{STZ}$ on 5 consecutive days, according to a previous study. ${ }^{27} \mathrm{STZ}$ was freshly diluted in cold sodium-citrate buffer $(0.1 \mathrm{M}$, $\mathrm{pH} 4.5$ ) and immediately used. STZ-treated rats received 5\% of glucose 24 hours after the first injection to reduce death due to hypoglycemic shock. In order to measure glucose levels, blood samples were taken from the tail vein after the last injection of STZ. All STZ-treated rats revealed fasting glycemia over $250 \mathrm{mg} / \mathrm{dL}$ and are used in our study.

\section{Treatment schedule}

The rats were randomly divided into five groups of eight animals, and treatments with $\mathrm{Fe}_{3} \mathrm{O}_{4} \mathrm{NPs}, \mathrm{QC}, \mathrm{QC}-\mathrm{Fe}_{3} \mathrm{O}_{4}$, and vehicle were initiated 5 days after the last injection of STZ. The dose of QC ( $25 \mathrm{mg} / \mathrm{kg}$, as standard dose) and duration of supplementation ( 35 days) were selected according to previous reports designating its effectiveness on the improvement of memory. ${ }^{20,21,28-31}$ All of the treatments were dissolved in DI water and gavaged (08:00-10:00 am) in separate groups of rats.

Group 1: Rats in the control group were treated with a vehicle of QC (DI water) for 35 days.

Group 2: Rats in the diabetic group were treated with a vehicle of QC (DI water) for 35 days.

Group 3: Rats in the diabetic group were treated with $25 \mathrm{mg} / \mathrm{kg} /$ day of free QC solution for 35 days.

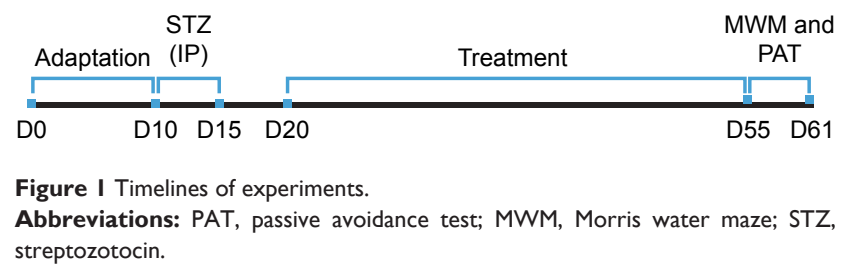

Group 4: Rats in the diabetic group were treated with $25 \mathrm{mg} / \mathrm{kg} /$ day $\mathrm{Fe}_{3} \mathrm{O}_{4}$ NPs for 35 days.

Group 5: Rats in the diabetic group were treated with $25 \mathrm{mg} / \mathrm{kg} /$ day $\mathrm{QC}-\mathrm{Fe}_{3} \mathrm{O}_{4}$ NPs for 35 days.

During the experiment, the blood glucose levels were measured seven times: two times before the beginning of treatment, the beginning of treatment, and four times after the treatment at intervals of 10 days. Body weight was also measured daily during the experiment. The timeline of experiments is shown in Figure 1.

\section{Behavioral parameters Morris water maze (MWM) test}

MWM test was conducted as an index of the spatial memory. The procedure was done according to the previous protocols with some certain minor modifications. ${ }^{32,33}$ The water maze consisted of a large circular swimming pool $(180 \mathrm{~cm}$ diameter, $50 \mathrm{~cm}$ height $)$ full of water $\left(23^{\circ} \mathrm{C} \pm 2^{\circ} \mathrm{C}\right)$ to a depth of $30 \mathrm{~cm}$ that was divided into four equal quadrants, labeled $1-2-3-4$. A round platform was placed $\sim 1 \mathrm{~cm}$ below the surface of the water in a constant position in quadrant 2 (the target quadrant) inside the pool. The pool was located in a dark room with a number of fixed visual cues hung on the wall, and the water was colored with powder milk to hide the position of the submerged platform. Rats were placed into the different quadrants and trained to swim to reach a hidden platform for 5 consecutive days and four training courses per day. A trial terminated when the animal reached the platform during 90 seconds; otherwise, failed rat was gently guided toward the platform and allowed to rest there for 30 seconds and returned to the cage. The probe trial was performed 24 hours after the last training session, the same as the training trial, except that the hidden platform was removed and each rat was allowed to search for it for 60 seconds. In the probe trial, each rat was released in the opposite quadrant of the platform facing the pool wall, and the retention of the spatial memory was evaluated by analyzing the time spent in the target quadrant. The time taken to reach the hidden platform in each trial day (escape latency), the time spent by each rat in the target quarter at probe trial day, and other parameters were measured. All behavior parameters were 
monitored by a video camera, fixed to the ceiling above the center of the pool and connected to a computerized tracking system (video tracking Software, Designed by BorjSanat Company, Tehran, Iran).

\section{Passive avoidance test}

Passive avoidance performance was conducted in shuttlebox apparatus. The apparatus and procedure for the passive avoidance test were the same as our previous report, with some modifications. ${ }^{34}$ Briefly, the shuttle-box consists of two compartments of the same size, illuminated, and dark $\left(30 \times 25 \times 25 \mathrm{~cm}^{3}\right)$ separated by a sliding door. The floor of the dark compartment was made of stainless steel rods that could be electrified using a shock generator. On day 1 (training), each rat was placed gently into the white chamber for 5 seconds and let to move into the dark chamber by opening the door. Each rat was kept in the dark room for 30 seconds for habituation training. After 30 minutes, the previous step was repeated for each rat, but when individual rat entered into the dark chamber, the sliding door was immediately closed and an electrical shock (0.3 mA, 1 seconds) was delivered (acquisition training). After 30 seconds, the rat was removed and returned to the home cage, and the same procedure was performed 2 minutes later to examine short-term memory formation. If the animal remained in the white compartment for 120 seconds, the test would be terminated; otherwise, the test was repeated and each rat received the shock again. Probe trial (retention trial) was conducted 24 hours after training. The procedure was performed the same as acquisition training without any shock. The rats were again positioned in the light chamber, and the time to enter the dark compartment was recorded as step-through latency (STL). The time spent in the dark compartment (TDC) was also recorded and considered as the memory retention. A maximum retention latency of 600 seconds was given to each rat.

\section{Pathohistological study}

At the end of the study to examine histopathologic alterations of normal and treated rats, the animals were killed by ketamine anesthesia. Pancreas, liver, kidney, and brain were removed and fixed instantaneously in $10 \%$ formalin in order to routine paraffin embedding. Paraffin blocks with 2-3 $\mu \mathrm{m}$ thickness were prepared and stained with hematoxylin-eosin method. Finally, the sections were examined under a Leitz microscope at $400 \times$ magnification.

\section{Statistical analysis}

All results were reported as mean \pm SEM. The one-way or two-way ANOVA followed by Tukey's multiple comparison tests or Student's $t$-test were used for data analysis. Statistical analysis was performed using GraphPad Prism software version 7 and $P<0.05$ was considered as statistically significant. For morphometric analysis, ImageJ software was used.

\section{Results $\mathrm{QC}-\mathrm{Fe}_{3} \mathrm{O}_{4}$}

Physical and chemical properties of dextran-coated $\mathrm{Fe}_{3} \mathrm{O}_{4}$ NPs, QC, and QC-conjugated magnetite NPs $\left(\mathrm{QC}-\mathrm{Fe}_{3} \mathrm{O}_{4}\right)$ are shown in Figure 2. The FTIR spectrum of dextran-coated $\mathrm{Fe}_{3} \mathrm{O}_{4}$ NPs showed a strong absorption band at $3,386 \mathrm{~cm}^{-1}$ that confirmed the successful conjugation of QC on the $\mathrm{Fe}_{3} \mathrm{O}_{4}$ NPs (Figure 2A). The powder XRD pattern of the synthesized magnetic NPs revealed that this is close to the pattern for crystalline magnetite $\mathrm{Fe}_{3} \mathrm{O}_{4}$ (Figure $2 \mathrm{~B}$ ). The scanning electron microscopy results of exterior morphology and size of QC-conjugated $\mathrm{Fe}_{3} \mathrm{O}_{4} \mathrm{NPs}$ showed that the NPs are spherical and have diameters in the range of 30-50 nm (Figure 2C). The presence of iron and oxygen was also confirmed by the EDX detector coupled to the scanning electron microscope (Figure 2D).

\section{Blood glucose levels and body weight}

Table 1 shows the results of measuring body weights. There was no significant difference in the average of body weight between groups before the onset of the study $(P>0.05)$, but after the last injection of STZ, the body weight of diabetic rats began to decrease. Forty-five days after diabetes induction (day 60), body weight decreased significantly in diabetic rats compared to control rats $(P<0.0001)$. Ten days after the initiation of treatment with $\mathrm{QC}-\mathrm{Fe}_{3} \mathrm{O}_{4}$, weight gain of this group was significant $(P<0.01)$, but after 30 days of treatment, a slight weight loss $(P>0.05)$ was observed in these rats and remained almost constant until the end of the study. Twenty days after treatment with QC, the weight of rats increased significantly $(P<0.01)$ and remained high until the end of the experiment. Treatment with $\mathrm{Fe}_{3} \mathrm{O}_{4}$ NPs did not influence $(P>0.05)$ on the body weights as compared to diabetic rats during the treatment (Table 1). Briefly, at the end of the study, the body weights in the conjugated $(P<0.05)$ and pure QC groups significantly $(P<0.01)$ increased compared to the diabetic rats, but weight loss remained significant in comparison with the non-diabetic control (NDC) group during treatment (Figure 3A).

As shown in Figure 3B, after diabetic induction (day 20), blood glucose levels were highly elevated in diabetic rats in comparison with control rats $(P<0.0001)$. Treatment with $\mathrm{QC}-\mathrm{Fe}_{3} \mathrm{O}_{4}(P<0.05)$ and $\mathrm{QC}$ caused a significant decline in 
A

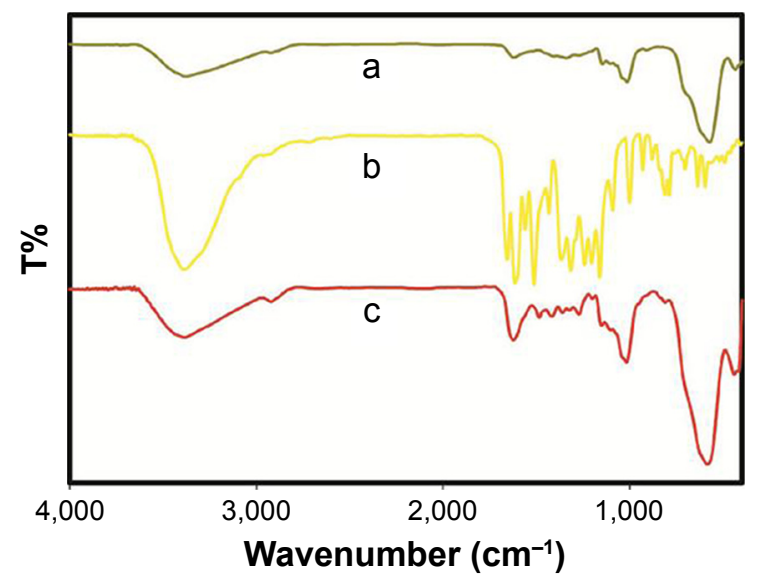

C

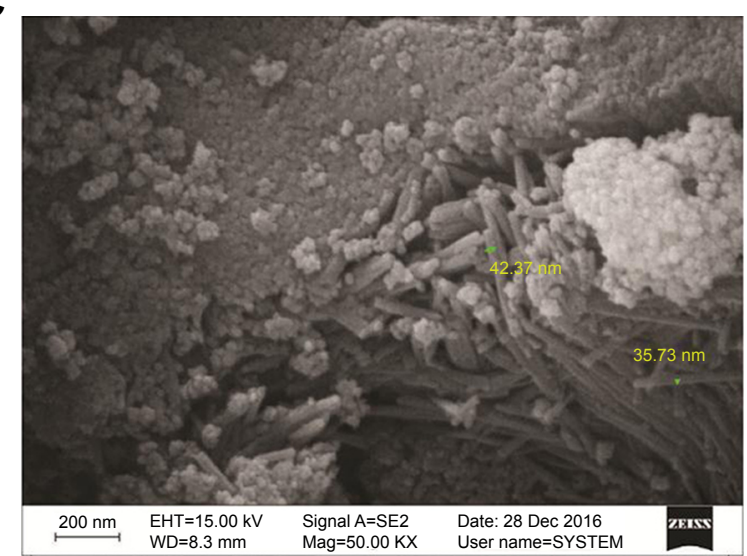

B

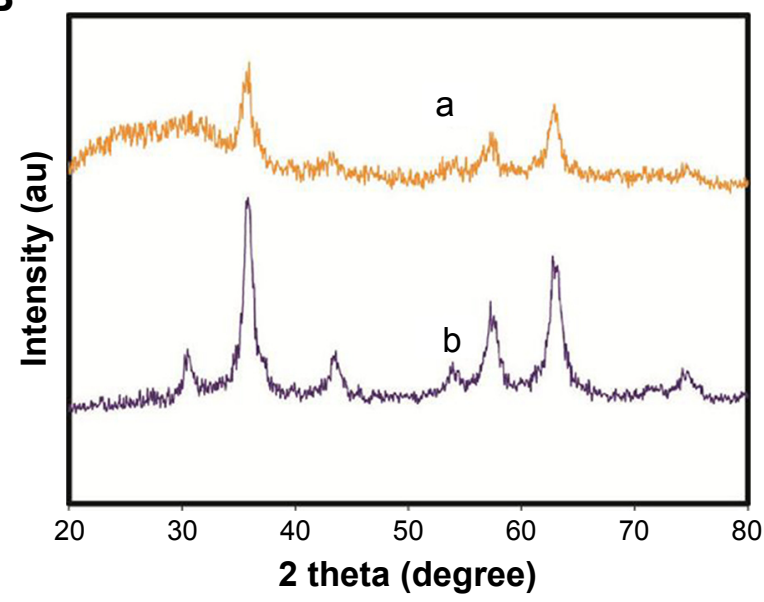

D

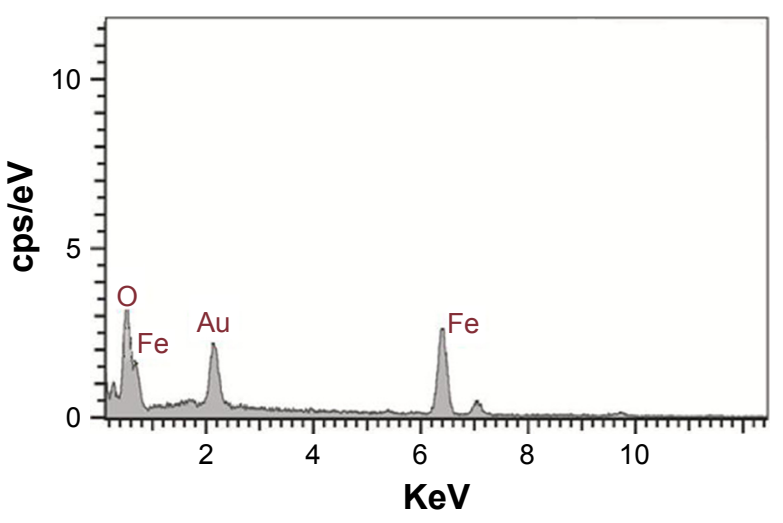

Figure 2 Characterization of $\mathrm{QC}-\mathrm{Fe}_{3} \mathrm{O}_{4}$. FT-IR spectra for the (A) dextran-coated, (B) pure QC, and (C) QC-conjugated Fe $\mathrm{O}_{4}$ nanoparticles $(\mathbf{A})$. $\mathrm{XRD}$ pattern of the (A) dextran-coated and (B) QC-conjugated $\mathrm{Fe}_{3} \mathrm{O}_{4}$ nanoparticles (B). Scanning electron microscopy image of $\mathrm{QC}_{\text {-conjugated Fe }} \mathrm{O}_{4}$ nanoparticles (C). Scanning electron microscope-EDX spectrum of QC-conjugated $\mathrm{Fe}_{3} \mathrm{O}_{4}$ nanoparticles (D).

Abbreviations: FT-IR, Fourier transform infrared; QC, quercetin; XRD, X-ray diffraction.

blood glucose level in diabetic rats $(P<0.01)$, although the elevated blood sugar in these groups was significant compared to the NDC rats until the end of the treatment. Treatment with $\mathrm{Fe}_{3} \mathrm{O}_{4}$ NPs had no significant effect $(P>0.05)$ on blood glucose levels in diabetic rats during the treatment, such as body weight.

\section{Effects of treatments on the performance of the MWM test}

The spatial memory was investigated in the MWM test. The mean escape latency for trained rats reduced during the 20 training sessions in all groups. Control diabetic rats significantly exhibited higher escape latency on the days $2,3,4$,

Table I Body weight of control, diabetic rats, and those treated with $\mathrm{Fe}_{3} \mathrm{O}_{4} \mathrm{NP}, \mathrm{QC}$, and $\mathrm{QC}-\mathrm{Fe}_{3} \mathrm{O}_{4} \mathrm{NPs}$ at 20 and 10 days before treatment, the onset of treatment, 10, 20,30, and 40 days after the beginning of treatment

\begin{tabular}{|l|l|l|l|l|l|l|l|}
\hline \multirow{2}{*}{ Groups (n=8) } & \multicolumn{6}{l|}{ Body weight (g) } \\
\cline { 2 - 8 } & Day 0 & Day 10 & Day 20 & Day 30 & Day 40 & Day 50 & Day 60 \\
\hline NDC & $203.8 \pm 4.79$ & $229.6 \pm 5.86$ & $244.8 \pm 3.58$ & $254.3 \pm 4.60$ & $266.4 \pm 4.31$ & $277.9 \pm 4.38$ & $283.6 \pm 5.16$ \\
DC & $210.0 \pm 5.08$ & $239.9 \pm 6.42$ & $224.1 \pm 5.45^{* *}$ & $219.8 \pm 6.97^{* *}$ & $215.9 \pm 8.41^{* * *}$ & $216.3 \pm 10.15^{* * * *}$ & $214.9 \pm 9.70^{* * *}$ \\
D+NP $(25 \mathrm{mg} / \mathrm{kg})$ & $206.9 \pm 6.33$ & $235.3 \pm 7.18$ & $221.8 \pm 7.09$ & $231.6 \pm 9.91$ & $234.0 \pm 9.52$ & $236.4 \pm 8.97$ & $240.9 \pm 11.13$ \\
D+QC $(25 \mathrm{mg} / \mathrm{kg})$ & $205.6 \pm 5.93$ & $234.6 \pm 6.13$ & $223.0 \pm 4.93$ & $232.6 \pm 5.79$ & $237.5 \pm 5.13^{\#}$ & $248.5 \pm 5.14^{\#}$ & $256.8 \pm 5.54^{\# \#}$ \\
D+QCNP $(25 \mathrm{mg} / \mathrm{kg})$ & $213.8 \pm 6.86$ & $243.3 \pm 7.73$ & $237.4 \pm 3.51$ & $248.6 \pm 3.9 I^{\#}$ & $244.3 \pm 4.20^{\#}$ & $245.0 \pm 5.46^{\#}$ & $242.1 \pm 7.47^{\#}$ \\
\hline
\end{tabular}

Notes: ${ }^{*} P<0.05$ and ${ }^{\# P}<0.01$ against diabetic control group (one-way ANOVA followed by Tukey's post hoc test, $n=7-8$ ). $* * P<0.01$ and $* * * P<0.000$ I vs NDC group.

Abbreviations: DC, diabetic control; QC, quercetin; NP, nanoparticle; NDC, non-diabetic control; D+NP, diabetic treated with nanoparticle; D+QC, diabetic treated with quercetin; D+QCNP, diabetic treated with quercetin nanoparticle. 

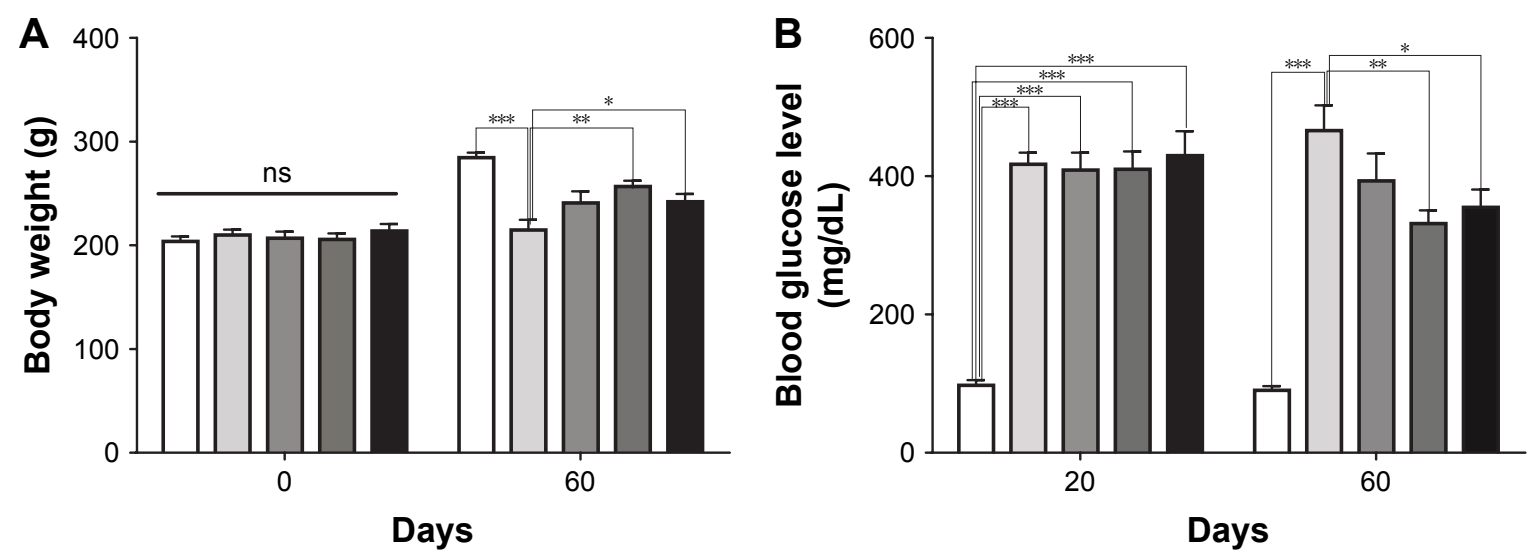

D+QCNP $\square \mathrm{D}+\mathrm{QC} \square \mathrm{D}+\mathrm{NP} \square \mathrm{DC} \square \mathrm{NDC}$

Figure 3 Effect of treatment with $\mathrm{Fe}_{3} \mathrm{O}_{4} \mathrm{NPs}, \mathrm{QC}, \mathrm{QC}-\mathrm{Fe}_{3} \mathrm{O}_{4} \mathrm{NPs}$ (35 days) on body weight $(\mathbf{A})$ and blood glucose levels (B) in STZ-induced diabetic rats. Notes: Each value is represented as mean \pm SEM of $7-8$ animals per group. $* P<0.05$, $* * P<0.01$, and $* * * P<0.000$ I vs diabetic control group (two-way ANOVA). Abbreviations: QC, quercetin; NP, nanoparticle; STZ, streptozotocin; NDC, non-diabetic control; DC, diabetic control; D+NP, diabetic treated with nanoparticle; $\mathrm{D}+\mathrm{QC}$, diabetic treated with quercetin; $\mathrm{D}+\mathrm{QCNP}$, diabetic treated with quercetin nanoparticle.

and 5 of training compared to non-diabetic rats. The mean escape latencies were similar on the first day of testing in all groups which indicates that swimming ability was not affected by hyperglycemia $(P>0.05)$. Two-way ANOVA followed by Tukey's multiple comparison tests showed that treatment with $\mathrm{QC}-\mathrm{Fe}_{3} \mathrm{O}_{4}(25 \mathrm{mg} / \mathrm{kg})$ significantly $(P<0.05$ and $P<0.01)$ decreased escape latency in diabetic rats on days $2,3,4$, and 5 compared to diabetic rats.

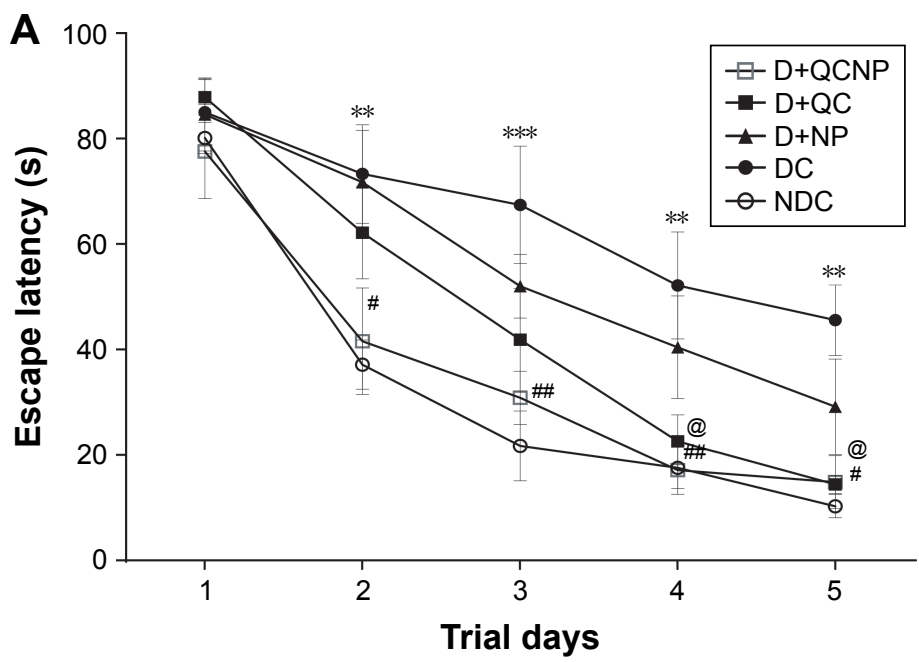

B

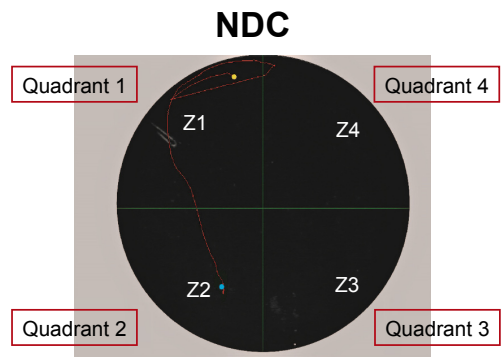

DC

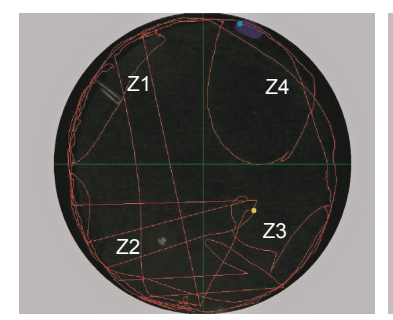

$\mathrm{D}+\mathrm{NP}$

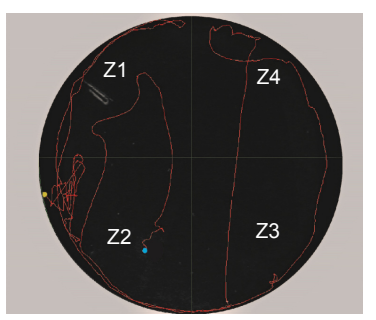

$D+Q C$

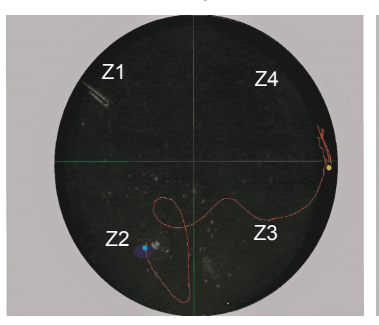

$D+Q C N P$

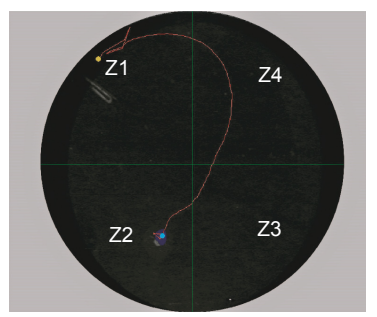

Figure 4 Effect of treatment with $\mathrm{Fe}_{3} \mathrm{O}_{4} \mathrm{NPs}, \mathrm{QC}, \mathrm{QC}-\mathrm{Fe}_{3} \mathrm{O}_{4} \mathrm{NPs}$ (35 days) on the performance of spatial memory acquisition phase in Morris water maze test. Average escape latency during the training days (A), swim path traces from the final training day (B). Each value expressed as mean \pm SEM of 7-8 animals per group. Statistical significance was determined using two-way ANOVA (followed by Tukey's multiple comparison test) at ${ }^{* *} P<0.01$ and $* * * P<0.000 \mathrm{I}$ vs NDC group. ${ }^{*} P<0.05$, ${ }^{\# * P}<0.0 \mathrm{I}$, and $@ P<0.05$ vs diabetic control group.

Abbreviations: QC, quercetin; NP, nanoparticle; NDC, non-diabetic control; DC, diabetic control; D+NP, diabetic treated with nanoparticle; D+QC, diabetic treated with quercetin; D+QCNP, diabetic treated with quercetin nanoparticle. 

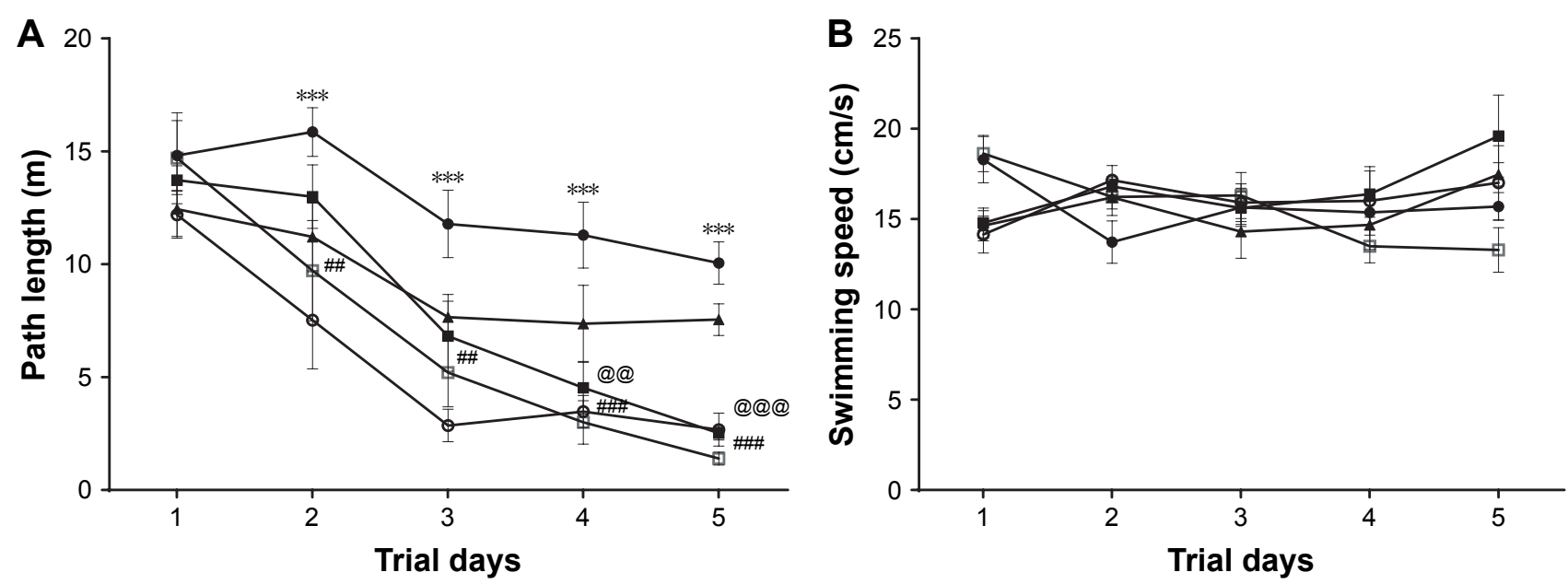

$-\square+Q C N P \rightarrow D+Q C \rightarrow D+N P \rightarrow D C \rightarrow N D C$

Figure 5 Comparison of swimming speed $(\mathbf{A})$ and traveled swimming distance (B) during training trial days. Values are represented as mean \pm SEM for 7-8 observations. Statistical significance was determined using two-way ANOVA (followed by Tukey's multiple comparison test) at $* * * P<0.00$ I vs NDC group. ${ }^{\#} P<0.0$ I, \#P $P<0.00$ I, @@P $<0.0$ I and @@@ $<0.001$ vs diabetic control group.

Abbreviations: QC, quercetin; NP, nanoparticle; NDC, non-diabetic control; DC, diabetic control; D+NP, diabetic treated with nanoparticle; D+QC, diabetic treated with quercetin; D+QCNP, diabetic treated with quercetin nanoparticle.

It is noteworthy that there was no significant difference $(P>0.05)$ in escape latency between this group and the control group during all the training days. Further analyzes indicated that treatment with QC $(25 \mathrm{mg} / \mathrm{kg})$ also prevented memory impairment, which was shown by reducing escape latency in diabetic rats on days 4 and 5 in comparison with control diabetic rats $(P<0.05)$. Treatment with $\mathrm{Fe}_{3} \mathrm{O}_{4}$ NPs $(25 \mathrm{mg} / \mathrm{kg})$ in diabetic animals had no significant $(P>0.05)$ improvements in escape latency over the training days (Figure 4A). In addition, a comparison of swimming path traces on the final trial day showed that the group treated with QC NPs traveled less to reach the platform (Figure 4B).

Figure 5A shows the swim path length in training days. The path lengths to reach the hidden platform in all groups were shortened during the training period. Two-way ANOVA analysis showed that treatment with QC alone $(P<0.05)$ and in conjugated with $\mathrm{Fe}_{3} \mathrm{O}_{4} \mathrm{NPs}(P<0.01)$ significantly reduced the pathway length in subsequent trial days $(P<0.05)$. The swimming speed during the acquisition test for all groups is shown in Figure 5B.

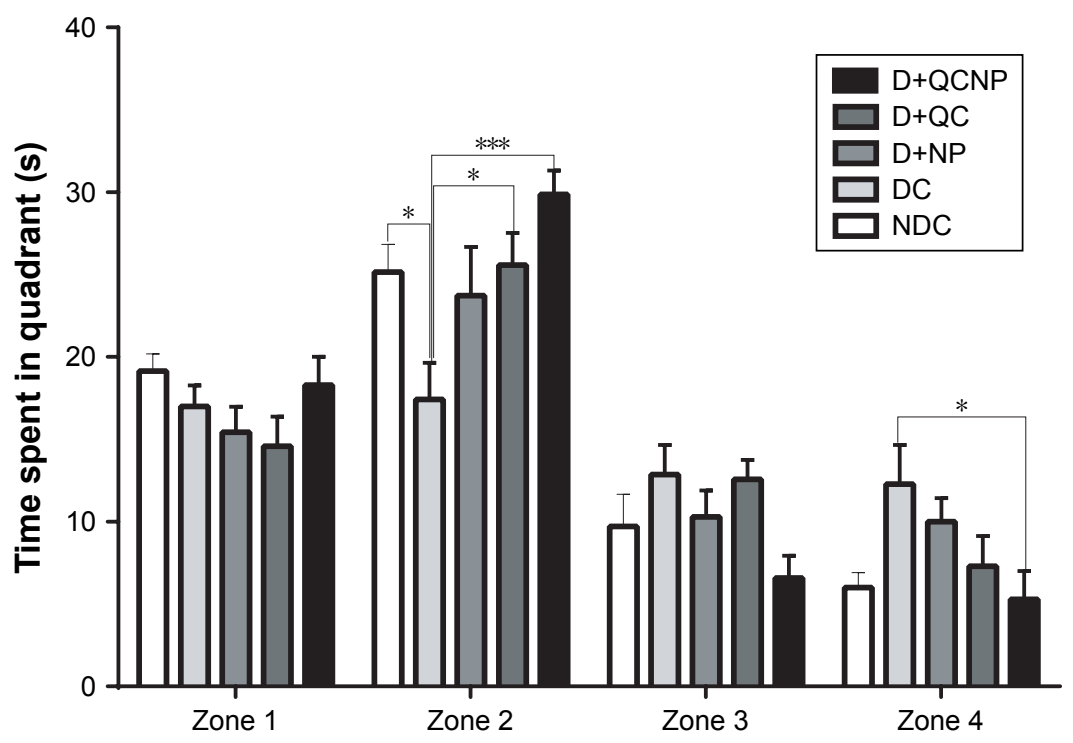

Figure 6 Effect of treatment with $\mathrm{Fe}_{3} \mathrm{O}_{4} \mathrm{NPs}, \mathrm{QC}, \mathrm{QC}-\mathrm{Fe}_{3} \mathrm{O}_{4} \mathrm{NPs}$ (35 days) on water maze performance in the probe trial. Probe trial performance was measured by the time spent in the target zone (zone 2). Values are represented as mean \pm SEM of $7-8$ animals per group. $* P<0.05$ and $* * * P<0.000$ I vs diabetic control group (two-way ANOVA followed by Tukey's multiple comparison test).

Abbreviations: QC, quercetin; NP, nanoparticle; NDC, non-diabetic control; DC, diabetic control; D+NP, diabetic treated with nanoparticle; D+QC, diabetic treated with quercetin; D+QCNP, diabetic treated with quercetin nanoparticle. 
There was no significant difference in mean swimming speed in different groups during the training period, indicating that all of the groups showed similar motor capabilities $(P>0.05)$.

Results from the probe trial are indicated in Figure 6, which provides the time spent in each of the four zones for all groups. The target zone preference (zone 2 in this research, where the platform was previously located) declined significantly in the diabetic group $(P<0.05)$ that indicates that the memory was impaired in this group. While treatment with $\mathrm{QC}-\mathrm{Fe}_{3} \mathrm{O}_{4}$ significantly prevented the memory dysfunction as indicated by increasing the time spent in the target quadrant $(P<0.001)$ and reducing the time spent in the opposite quadrant ( $\mathrm{Z} 4$ in this research) $(P<0.05)$. Pure QC treatment also prevented memory impairment in rats but showed less effect on the time spent in the target quadrant relative to the conjugated state $(P<0.05)$. The analyses showed that $\mathrm{Fe}_{3} \mathrm{O}_{4} \mathrm{NPs}$ had no influence $(P>0.05)$ on the preference of the target quadrant.

\section{Effects of treatments on the performance of passive avoidance learning test}

The result of passive avoidance task is shown in Figure 7. Statistical analysis revealed that there was no significant difference in the STL of the first acquisition trial between groups $(P>0.05)$. This result shows that five groups of animals revealed similar exploratory behavior in the absence of electrical shock (Figure 7A). One-way ANOVA showed significant differences in STL between experimental groups in the retention test. STL was dramatically lower in the diabetic group, which is another confirmation of the memory loss in this group. Treatment with $\mathrm{QC}$ and $\mathrm{QC}-\mathrm{Fe}_{3} \mathrm{O}_{4}$ significantly amplified STL in STZ group $(P<0.05)$, suggesting improvement effect of QC on memory retrieval.

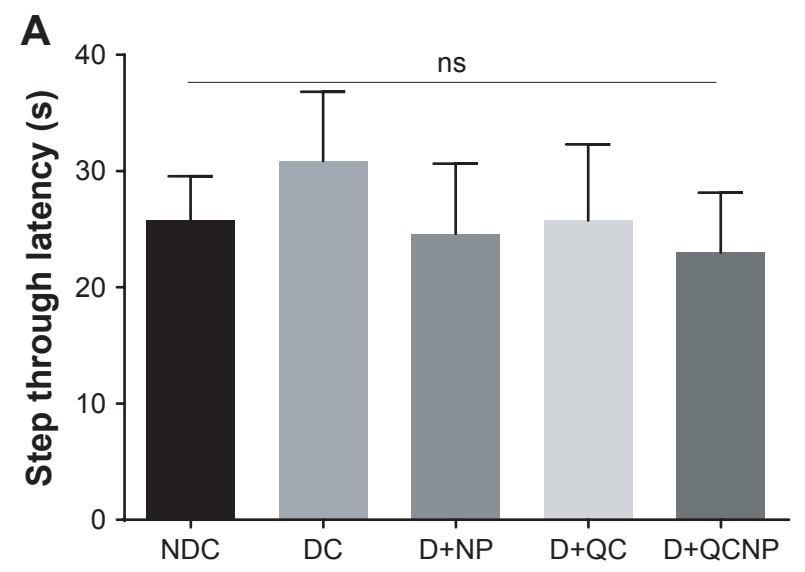

The other investigated criterion in retention test was TDC. As shown in Figure 8, TDC in the diabetic group was significantly increased compared to control. Post hoc analysis by Tukey's test revealed that treatments with both free and QC-conjugated NPs significantly decreased TDC in STZ groups. However, the maximum effect was observed with QC- $\mathrm{Fe}_{3} \mathrm{O}_{4}(P<0.01)$. Interestingly, $\mathrm{Fe}_{3} \mathrm{O}_{4} \mathrm{NP}$ treatment significantly reduced TDC $(P<0.05)$ in diabetic rats that exhibited improvement effect of $\mathrm{Fe}_{3} \mathrm{O}_{4} \mathrm{NPs}$ on memory and passive avoidance learning (PAL). Overall, the results of MWM and $\mathrm{PAL}$ tests revealed that $\mathrm{QC}-\mathrm{Fe}_{3} \mathrm{O}_{4}$ has high efficiency in increasing learning and memory than the free QC.

\section{Effects of treatments on histopathologic alterations}

Histology of the pancreas, liver, kidney, and brain tissues are shown in Figure 9. The pancreas tissue from control group rats showed a compact and round-shaped of pancreatic islet with a normal distribution. In the diabetic group, deformation of islets of Langerhans with a significant decrease in number of the islets and their area $(P<0.01)$ were observed relative to the control group (Figure 9A-C). After treatment with QC and $\mathrm{QC}-\mathrm{Fe}_{3} \mathrm{O}_{4}$, significant amelioration and regeneration in the structure of the islets of Langerhans were observed. In this respect, the number of islets and the islet area significantly increased in diabetic rats treated with QC $(P<0.05)$ and treated with $\mathrm{QC}-\mathrm{Fe}_{3} \mathrm{O}_{4}(P<0.05)$ groups as compared with diabetic group. Tissue sections from diabetic rats treated with $\mathrm{Fe}_{3} \mathrm{O}_{4}$ NPs showed expansion of pancreatic islet with partial regeneration of beta cells.

Hepatic sections of control rats showed a regular lobular pattern with a central vein, slit-like sinusoids, and prominent

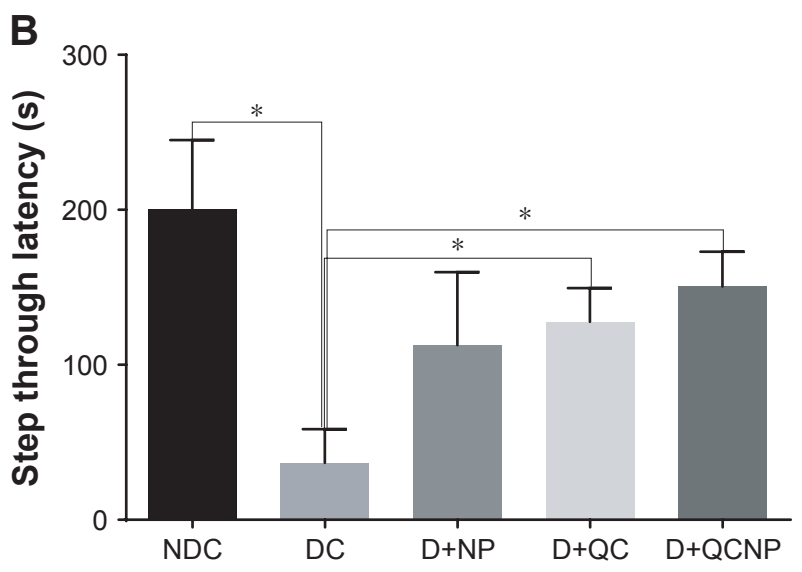

Figure 7 Effect of treatment with $\mathrm{Fe}_{3} \mathrm{O}_{4} \mathrm{NPs}, \mathrm{QC}, \mathrm{QC}-\mathrm{Fe}_{3} \mathrm{O}_{4} \mathrm{NPs}$ (35 days) on passive avoidance performance. STL in the first acquisition trial (A) and STL in the retention test (B). Each value represents mean \pm SEM of $7-8$ animals. $* P<0.05$ vs diabetic control group (one-way ANOVA followed by Tukey's test).

Abbreviations: QC, quercetin; NP, nanoparticle; NDC, non-diabetic control; DC, diabetic control; D+NP, diabetic treated with nanoparticle; D+QC, diabetic treated with quercetin; D+QCNP, diabetic treated with quercetin nanoparticle; STL, step-through latency. 


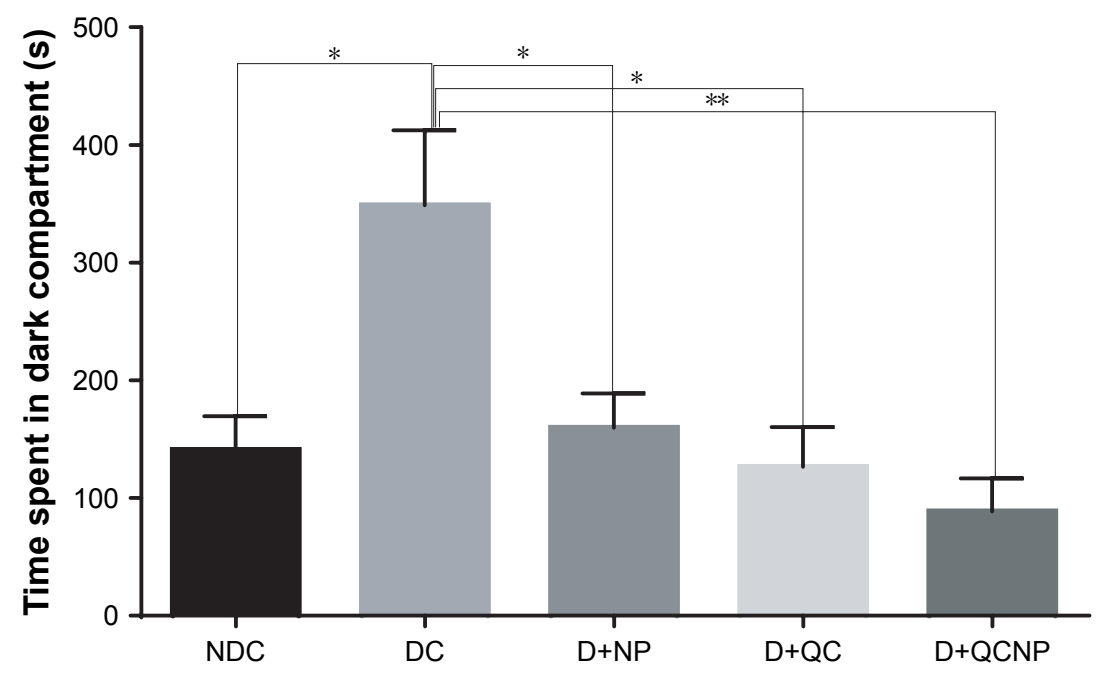

Figure 8 Effect of treatment with $\mathrm{Fe}_{3} \mathrm{O}_{4} \mathrm{NPs}, \mathrm{QC}, \mathrm{QC}-\mathrm{Fe}_{3} \mathrm{O}_{4} \mathrm{NPs}$ (35 days) on the time spent in the dark compartment in the retention test (TDC). Each value represents mean \pm SEM of $7-8$ animals. $* P<0.05$ and $* * P<0.01$ vs diabetic control group (one-way ANOVA followed by Tukey's test).

Abbreviations: QC, quercetin; NP, nanoparticle; NDC, non-diabetic control; DC, diabetic control; D+NP, diabetic treated with nanoparticle; D+QC, diabetic treated with quercetin; D+QCNP, diabetic treated with quercetin nanoparticle.

nuclei. While, histological alterations including distorted central vein, hepatocellular degeneration, and disrupted sinusoids including infiltration of blood were observed in the liver tissue of diabetic rats. Treatment with $\mathrm{QC}$ and $\mathrm{QC}-\mathrm{Fe}_{3} \mathrm{O}_{4}$ caused revival of hepatic lobular architecture. Furthermore, the histological slides of the NDC kidney revealed the presence of the normal renal corpuscle surrounded by Bowman's capsule, normal glomerulus containing a tuft of regular capillaries. In addition, epithelial lining and the urinary space were clearly visible in the sections of the kidney. In the case of DC group, distorted histomorphology such as modest glomerular lesions, irregular capillaries, and destructed epithelial lining were detected, but these abnormal histological signs dramatically restored in diabetic groups treated with $\mathrm{QC}$ and $\mathrm{QC}-\mathrm{Fe}_{3} \mathrm{O}_{4}$.

In the hippocampus, the granular cell layers of NDC dentate gyri contained densely arranged neurons. In diabetic brains, pyknotic nuclei were observed in many granular cells, suggesting apoptosis. In $\mathrm{QC}$ and $\mathrm{QC}-\mathrm{Fe}_{3} \mathrm{O}_{4}$-treated groups, most of the granular neurons were considered normal.

\section{Discussion}

The major finding of this study is that QCSPIONs could enhance learning and memory in diabetic rats with higher efficiency than pure QC. In spite of investigating the effect of pure QC, to the best of our knowledge, the present study is the first study evaluating QCSPIONs on diabetes-related cognitive dysfunction. Injections of multiple low doses of STZ were used to induce experimental type 1 diabetes in the tested rats. After the last injection of STZ, the level of blood sugar was significantly increased in diabetic rats and body weight significantly decreased in this group (Figure 3). In addition, at the end of the study period (45 days after DM induction), histological evaluation of pancreatic betacells revealed that the Langerhans islets and beta cells were destroyed in diabetic rats (Figure 9). These results confirmed that a successful diabetic model with a minimum mortality rate was induced in this way.

Experimental diabetes decreased learning and memory performance during 45 days. The MWM and PAL tests were performed to evaluate the spatial learning and fear memory, respectively. In the MWM test, a decrease in escape latency in repeated trial days and increased time spent in the target zone in the probe trial indicate the correct function of memory and learning. ${ }^{33}$ In diabetic rats, escape latency was higher than non-diabetic rats, and time spent in the target quadrant was less than non-diabetic rats. Since the mean latencies in the first trial and swimming speed during trial days in the diabetic group was similar to controls, it could be suggested that the hyperglycemia decreased learning and memory performance without any effect on the motor performance (ability to swim) (Figures 4, 5). Similarly, the PAL test in diabetic rats was also impaired when compared to non-diabetic rats, which confirmed the earlier test. In the PAL test, a decrease in STL and an increase in TDC in the retention test indicated impairment of memory. ${ }^{34}$ The analysis revealed that hyperglycemia significantly reduced STL and increased TDC in diabetic rats (Figures 7, 8). All of the results are consistent with previous studies that diabetes causes memory impairment. ${ }^{20,21,35}$ 

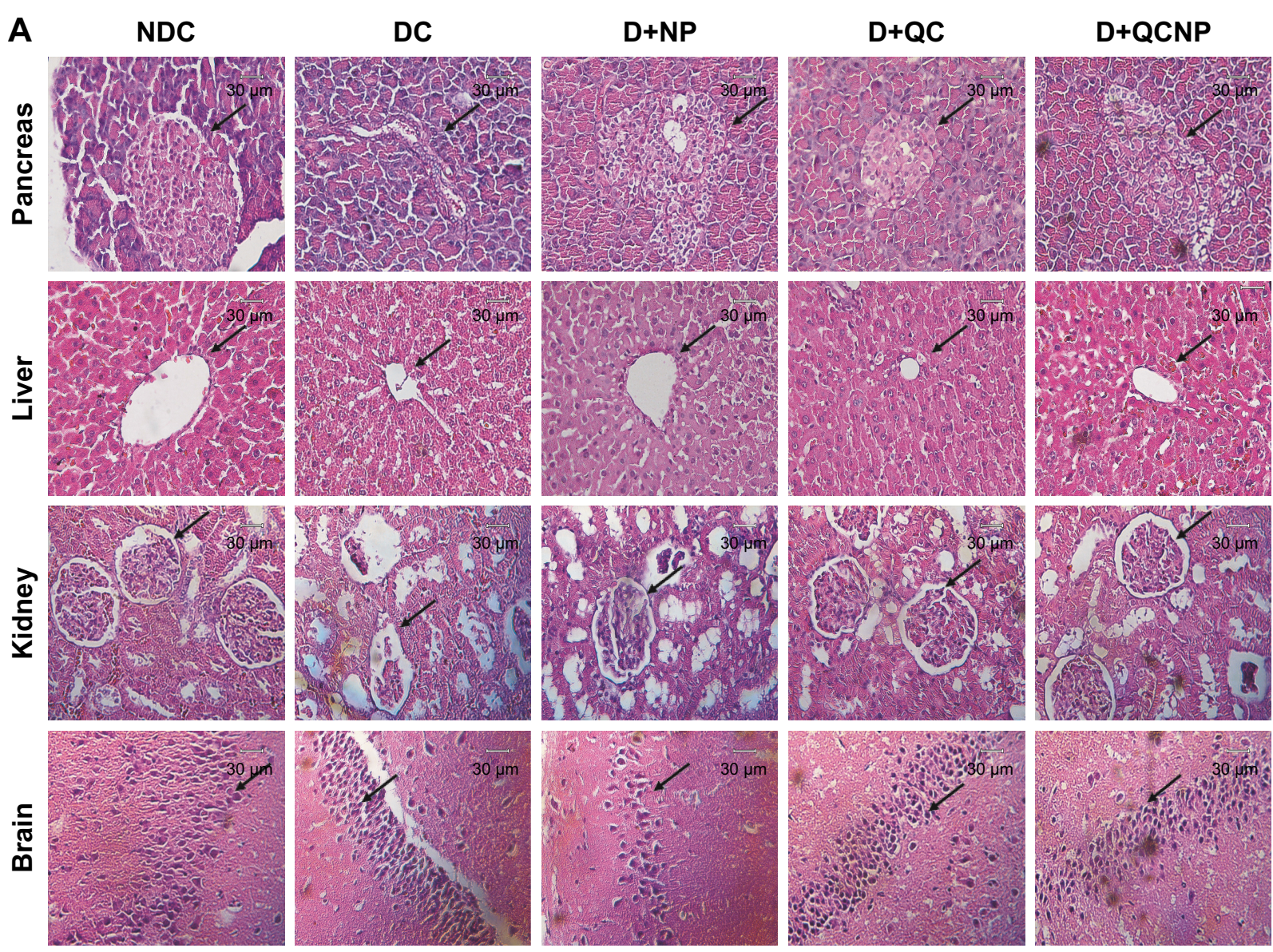

B

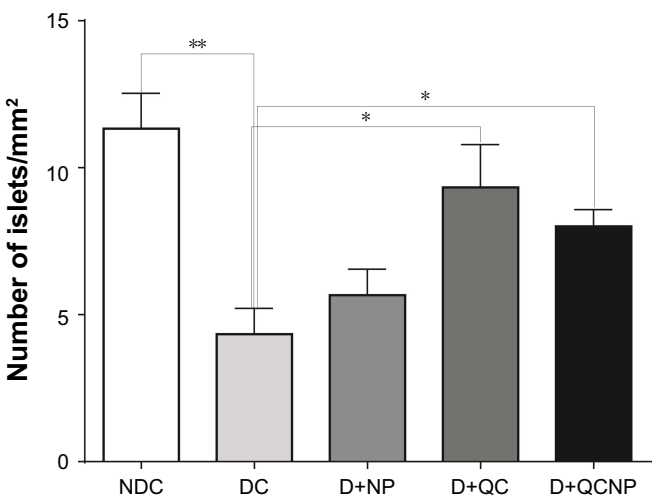

C

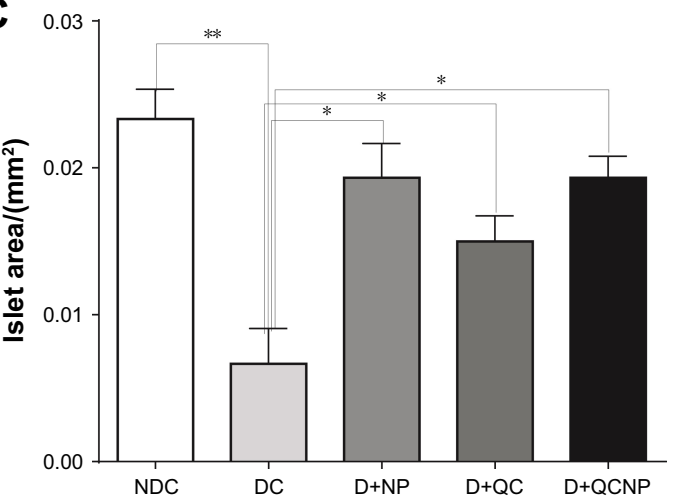

Figure 9 Photomicrographs of pancreas, liver, kidney, and brain sections after 35 days treatment with $\mathrm{Fe}_{3} \mathrm{O}_{4} \mathrm{NPs}, \mathrm{QC}, \mathrm{QC}-\mathrm{Fe} \mathrm{O}_{3} \mathrm{NPs}(\mathrm{H} \& \mathrm{E}$ staining, magnification $40 \times$, scale bar: $30 \mu \mathrm{m})(\mathbf{A})$. The arrows show islets in pancreas, bile duct in liver, glomerular in kidney, and cell nuclear density and cytoplasm in hippocampus. The number of pancreatic islets $/ \mathrm{mm}^{2}$ (B) and the islet area (C) was measured from whole pancreas sections taken from rats. $* P<0.05$ and $* * P<0.0$ I vs diabetic control group (one-way ANOVA followed by Tukey's test).

Abbreviations: QC, quercetin; NP, nanoparticle; H\&E, hematoxylin \& eosin; NDC, non-diabetic control; DC, diabetic control; D+NP, diabetic treated with nanoparticle; $\mathrm{D}+\mathrm{QC}$, diabetic treated with quercetin; $\mathrm{D}+\mathrm{QCNP}$, diabetic treated with quercetin nanoparticle.

QC, a polyphenol widely present in the human diet, has received the most attention in the CNS due to numerous neurobeneficial activities including free radical scavenging, anti-inflammatory properties, neuroprotection, and cognitive enhancing effects. ${ }^{36,37}$ In the present study, treatment with QC by gavage at dose $25 \mathrm{mg} / \mathrm{kg}$ once a day for 35 days improved spatial learning and memory retrieval in diabetic rats evidenced by improved performance in the MWM and
PAL tests. These results are also in accordance with earlier reports. In 2010, Bhutada et al showed that orally administered QC (5-20 mg/kg, twice daily, 30 days) in STZ-induced diabetic rats ameliorated the performance of the MWM test and elevated plus maze tasks. ${ }^{20}$ In 2016, Maciel et al also showed that QC administration by gavage $(5-50 \mathrm{mg} / \mathrm{kg}$, once daily, 40 days) was able to prevent the impairment of memory induced by STZ-diabetes. ${ }^{21}$ Generally, the beneficial effects 
of QC on learning and memory that has been observed in the present study could be because of several reasons. 1) QC acts as a direct antioxidant due to the presence of two pharmacophores inside its structure and indirect antioxidant by stimulating cellular defenses against oxidative stress. ${ }^{19}$ The roles of oxidative stress in neuronal damage, $A \beta$ pathology, and cognitive dysfunctions in diabetic condition have been studied. ${ }^{16}$ Therefore, the protective effect of QC on diabetesrelated cognitive impairment may be due to its antioxidant effect. 2) QC possesses beneficial anti-inflammatory properties through the inhibition of NF- $\mathrm{KB}$ pathway and reduction of pro-inflammatory cytokines such as tumor necrosis factor- $\alpha$, interleukin (IL)-1 $\beta$, and IL-6. ${ }^{38,39}$ It has been reported that increasing the activity of NF- $\mathrm{KB}$ and the concentration of pro-inflammatory mediators in the brain of diabetic rats is associated with a loss of synapse and impaired cognition. ${ }^{11,40}$ Therefore, the protective effect of QC could be due to its role in reducing neuroinflammation. 3) Some studies have shown that QC enhances phosphorylation and expression of cAMP response element-binding protein (CREB). It is noteworthy that the reduction of CREB expression in the brain of diabetics is associated with cognitive decline. ${ }^{41}$ Hence, the inhibitory effect of QC on diabetes-relevant cognitive inefficiencies might also involve CREB activation. 4) Additionally, the ability of QC in the inhibition of acetylcholine esterase (AChE) has been widely reported. Since the induced activity of AchE has been shown in the diabetics brain to be a hallmark of the cognition dysfunction, QC may play a role in preventing cognitive dysfunctions associated with diabetes through inhibiting AChE.

In this study, treatment with QC also effectively reduced the blood glucose levels and prevented the body weight loss in diabetic rats. Some studies also demonstrated antidiabetic properties of QC through a variety of mechanisms. ${ }^{42-44}$ On the other hand, the relationship between prolonged hyperglycemia and cognitive impairment has been reported. ${ }^{45}$ Therefore, part of the memory restoration that is found in diabetic rats could be due to the potency of QC to decrease hyperglycemia and improve other diabetic-related parameters such as dyslipidemia.

Despite the beneficial effects, QC has poor solubility and difficulty crossing the BBB. An in vivo study demonstrated that after a single intraperitoneal injection of QC (30 mg/kg), no QC was detected in the rat brains during the period 30 minutes to 4 hours. ${ }^{46}$ In another study in pigs, after $50 \mathrm{mg} / \mathrm{kg}$ daily QC intake for 4 weeks, only $0.02 \mu \mathrm{M}$ QC was found in the brain tissue. ${ }^{47}$ In order to overcome this important challenge, we conjugated QC on SPIONs. The results of the MWM test revealed that treatment with $\mathrm{QC}-\mathrm{Fe}_{3} \mathrm{O}_{4}$ significantly decreased the escape latency of diabetic rats on the second day of their training, whereas treatment with pure QC reduced the escape latency on the fourth day of training (Figure 4). Treatment with $\mathrm{QC}-\mathrm{Fe}_{3} \mathrm{O}_{4}$ also increased significantly the time spent in the target zone of the probe trial in diabetic rats when compared with rats that received pure QC (Figure 6). The result of the PAL test also revealed that treatment with $\mathrm{QC}-\mathrm{Fe}_{3} \mathrm{O}_{4}$ significantly increased STL and decreased TDC in STZ groups (Figures 7 and 8). It has been reported that dextran increased the stability of NPs in the bloodstream. ${ }^{48}$ Therefore, it could be proposed that dextrancoated NPs increase the stability of QC in the bloodstream for a longer time and lead to better results in learning and memory. A study in 2015 showed that oral delivery of QC conjugated with poly(n-butyl cyanoacrylate) NPs enhanced its distribution in the brain of Wistar rats by 2.38 -fold relative to QC in the pure form. ${ }^{49}$ Recently, we reported that the concentration of conjugated QC in the brain of healthy rats is higher than the pure form, 24 hours after oral administration of QC conjugate with iron oxide NPs (under submission). We measured the concentration of QC in the brain and plasma, after treatment with either free QC or QCSPIONs by means of HPLC. Reverse-phase HPLC with UV detector and the C18 column was used to measure the concentrations of QC and QC conjugate with iron oxide NPs in the brain. The results of this study showed that QC concentrations in the brain after oral administration of QC in the conjugate state with a dose of 50 and $100 \mathrm{mg} / \mathrm{kg}$ was about 4.8 and 8.6 times, respectively, higher than QC in the pure form.

In the present study, the drug loading and drug-releasing for $\mathrm{QC}-\mathrm{Fe}_{3} \mathrm{O}_{4}$ conjugate were obtained as $42 \%$ and $61.6 \%$, respectively. Based on these results, it can be concluded that the dose of QC in the conjugated form is significantly lower than free QC dose because only one part of the construct was composed of QC. Therefore, we proposed that superparamagnetic $\mathrm{Fe}_{3} \mathrm{O}_{4}$ NPs will lead to more efficiency of QC on learning and memory via enhancing its bioavailability. It is noteworthy that $\mathrm{Fe}_{3} \mathrm{O}_{4}$ NPs enter the cell through endocytosis depending on their size, so it can be suggested that NPs increase the penetration of QC into brain cells through the endocytosis process. ${ }^{50}$

In addition, treatment with $\mathrm{QC}-\mathrm{Fe}_{3} \mathrm{O}_{4}$ significantly increased the body weight of diabetic rats on the 10th day after treatment, but after 30 days of treatment, a slight weight loss was observed in these rats (Table 1). In a research conducted by Szalay et al, injection of $5 \mathrm{mg} / \mathrm{kg} \mathrm{Fe}_{3} \mathrm{O}_{4} \mathrm{NP}$ for 7 days led to a significant weight loss in treated rats. ${ }^{51}$ Therefore, it could 
be concluded that the observed weight loss could be due to an oxidative stress induced by $\mathrm{Fe}_{3} \mathrm{O}_{4} \mathrm{NPs}$. We also observed that QC- $\mathrm{Fe}_{3} \mathrm{O}_{4}$ decreased the blood glucose level of the diabetic rats the same as pure QC did. This result is consistent with the Alam et al report that observed a significant reduction of blood glucose levels in the QCNP supplemented group. ${ }^{52}$ In the present study, normal levels of blood glucose were not reached in the treatment groups due to permanent damage of $\beta$-cells in the pancreas by hyperglycemia. This observation is consistent with previous results and suggests that antidiabetic activity of QC is not sufficient to overcome permanent hyperglycemia. ${ }^{53}$ Finally, histological analysis showed that treatment with both $\mathrm{QC}-\mathrm{Fe}_{3} \mathrm{O}_{4}$ and pure QC restored the shape of beta islands and increased the number of islets and their area in diabetic rats. Treatment with QC in pure and conjugated states also preserved the liver lobular architecture and caused revival and recovery of distorted sinusoids. However, the recovery effect appeared to be better in the $\mathrm{QC}-\mathrm{Fe}_{3} \mathrm{O}_{4}$ group compared to the QC group. Furthermore, renal abnormal histological signs were dramatically improved in $\mathrm{QC}-\mathrm{Fe}_{3} \mathrm{O}_{4}$ and QC-treated diabetic rats (Figure 9). These results are consistent with new reports that QC NPs can assist in cellular regeneration. ${ }^{44,54}$ These results are also confirmed by our new study that showed QC and QCNP (50 and $100 \mathrm{mg} / \mathrm{kg}$ ) have no toxic effects on the liver and kidney of normal rats. This study did not show a significant difference in hepatic and renal AST, ALT, ALP, GGT, and LDH activities between control and treated groups. ${ }^{55}$ In these studies, the concentration of QC in the conjugated form was significantly lower than free QC concentration because only one part of the construct was composed of QC. Therefore, we can propose that the lower dosage of QC in the conjugate state could have a higher potential than pure QC.

\section{Conclusion}

Our results suggest SPIONs with minimal toxicity on body weight, blood glucose level, and body tissues to be a favorable candidate for oral delivery of QC. Subsequently, we should say that like many studies, cell experiments are needed to confirm the results obtained by the behavioral and histopathologic analysis. We have opened a new window in the assessment of the influencing mechanisms of QC in increasing learning and memory which can be also enhanced through conjugation it with superparamagnetic $\mathrm{Fe}_{3} \mathrm{O}_{4}$ NPs.

\section{Acknowledgments}

This work was supported by the grant from the University of Isfahan. The authors thank Dr Zari Pahlevanneshan of the University of Isfahan for her assistance with NP preparation.

\section{Disclosure}

The authors report no conflicts of interest in this work.

\section{References}

1. American Diabetes Association. 2. Classification and Diagnosis of Diabetes: Standards of Medical Care in Diabetes-2018. Diabetes Care. 2018;41(Suppl 1):S13-S27.

2. Ott A, Stolk RP, van Harskamp F, Pols HA, Hofman A, Breteler MM. Diabetes mellitus and the risk of dementia: The Rotterdam Study. Neurology. 1999;53(9):1937.

3. Strachan MW, Reynolds RM, Marioni RE, Price JF. Cognitive function, dementia and type 2 diabetes mellitus in the elderly. Nat Rev Endocrinol. 2011;7(2):108-114.

4. Rodill LG, Gilsanz P, Quesenberry CP, et al. Acute glycemic events and risk of dementia in older patients with type 1 diabetes. Alzheimers Dement. 2017;13(7):P564.

5. Kuo CL, Lu CL, Chang YH, Li CY. Population-Based Cohort Study on Dementia Risk in Patients with Type 1 Diabetes Mellitus. Neuroepidemiology. 2018;50(1-2):57-62.

6. Ramos-Rodriguez JJ, Molina-Gil S, Ortiz-Barajas O, et al. Central proliferation and neurogenesis is impaired in type 2 diabetes and prediabetes animal models. PLoS One. 2014;9(2):e89229.

7. Wrighten SA, Piroli GG, Grillo CA, Reagan LP. A look inside the diabetic brain: Contributors to diabetes-induced brain aging. Biochim Biophys Acta. 2009;1792(5):444-453.

8. Beauquis J, Saravia F, Coulaud J, et al. Prominently decreased hippocampal neurogenesis in a spontaneous model of type 1 diabetes, the nonobese diabetic mouse. Exp Neurol. 2008;210(2):359-367.

9. Guo J, Yu C, Li H, et al. Impaired neural stem/progenitor cell proliferation in streptozotocin-induced and spontaneous diabetic mice. Neurosci Res. 2010;68(4):329-336.

10. Sims-Robinson C, Kim B, Rosko A, Feldman EL. How does diabetes accelerate Alzheimer disease pathology? Nat Rev Neurol. 2010;6(10): 551-559.

11. Pugazhenthi S, Qin L, Reddy PH. Common neurodegenerative pathways in obesity, diabetes, and Alzheimer's disease. Biochim Biophys Acta. 2017;1863(5):1037-1045.

12. Li XH, Lv BL, Xie JZ, Liu J, Zhou XW, Wang JZ. AGEs induce Alzheimer-like tau pathology and memory deficit via RAGE-mediated GSK-3 activation. Neurobiol Aging. 2012;33(7):1400-1410.

13. Grilli M, Goffi F, Memo M, Spano P. Interleukin-1 beta and glutamate activate the NF-kappaB/Rel binding site from the regulatory region of the amyloid precursor protein gene in primary neuronal cultures. $J$ Biol Chem. 1996;271(25):15002-15007.

14. Bourne KZ, Ferrari DC, Lange-Dohna C, Rossner S, Wood TG, PerezPolo JR. Differential regulation of BACE1 promoter activity by nuclear factor-kappaB in neurons and glia upon exposure to beta-amyloid peptides. J Neurosci Res. 2007;85(6):1194-1204.

15. Alexiou P, Chatzopoulou M, Pegklidou K, Demopoulos VJ. RAGE: a multi-ligand receptor unveiling novel insights in health and disease. Curr Med Chem. 2010;17(21):2232-2252.

16. Baglietto-Vargas D, Shi J, Yaeger DM, Ager R, LaFerla FM. Diabetes and Alzheimer's disease crosstalk. Neurosci Biobehav Rev. 2016;64: 272-287.

17. Giacco F, Brownlee M. Oxidative stress and diabetic complications. Circ Res. 2010;107(9):1058-1070.

18. Chakraborty S, Stalin S, Das N, Choudhury ST, Ghosh S, Swarnakar S. The use of nano-quercetin to arrest mitochondrial damage and MMP-9 upregulation during prevention of gastric inflammation induced by ethanol in rat. Biomaterials. 2012;33(10):2991-3001.

19. Costa LG, Garrick JM, Roquè PJ, Pellacani C. Mechanisms of neuroprotection by quercetin: counteracting oxidative stress and more. Oxid Med Cell Longev. 2016;2016:1-10. 
20. Bhutada P, Mundhada Y, Bansod K, et al. Ameliorative effect of quercetin on memory dysfunction in streptozotocin-induced diabetic rats. Neurobiol Learn Mem. 2010;94(3):293-302.

21. Maciel RM, Carvalho FB, Olabiyi AA, et al. Neuroprotective effects of quercetin on memory and anxiogenic-like behavior in diabetic rats: Role of ectonucleotidases and acetylcholinesterase activities. Biomed Pharmacother. 2016;84:559-568.

22. Ganesan P, Ko HM, Kim IS, Choi DK. Recent trends in the development of nanophytobioactive compounds and delivery systems for their possible role in reducing oxidative stress in Parkinson's disease models. Int J Nanomedicine. 2015;10:6757.

23. Kim MK, Park KS, Yeo WS, Choo H, Chong Y. In vitro solubility, stability and permeability of novel quercetin-amino acid conjugates. Bioorg Med Chem. 2009;17(3):1164-1171.

24. Kumari A, Yadav SK, Pakade YB, Singh B, Yadav SC. Development of biodegradable nanoparticles for delivery of quercetin. Colloids Surf B Biointerfaces. 2010;80(2):184-192.

25. Kumar SR, Priyatharshni S, Babu VN, et al. Quercetin conjugated superparamagnetic magnetite nanoparticles for in-vitro analysis of breas cancer cell lines for chemotherapy applications. J Colloid Interface Sci. 2014;436:234-242.

26. Akal ZÜ, Alpsoy L, Baykal A. Superparamagnetic iron oxide conjugated with folic acid and carboxylated quercetin for chemotherapy applications. Ceram Int. 2016;42(7):9065-9072.

27. Hall KE, McDonald MW, Grisé KN, Campos OA, Noble EG, Melling CW The role of resistance and aerobic exercise training on insulin sensitivity measures in STZ-induced Type 1 diabetic rodents. Metabolism. 2013; 62(10):1485-1494.

28. Pattanashetti LA, Taranalli AD, Parvatrao V, Malabade RH, Kumar D. Evaluation of neuroprotective effect of quercetin with donepezil in scopolamine-induced amnesia in rats. Indian J Pharmacol. 2017; 49(1):60-64.

29. Pany S, Pal A, Sahu PK. Neuroprotective effect of quercetin in neurotoxicity induced rats: role of neuroinflammation in neurodegeneration Asian J Pharm Clin Res. 2014;7(4):152-156.

30. Mohammadi HS, Goudarzi I, Lashkarbolouki T, Abrari K, Elahdadi Salmani M, Salmani ME. Chronic administration of quercetin prevent spatial learning and memory deficits provoked by chronic stress in rats. Behav Brain Res. 2014;270:196-205.

31. Kumar A, Sehgal N, Kumar P, Padi SS, Naidu PS. Protective effect of quercetin against ICV colchicine-induced cognitive dysfunctions and oxidative damage in rats. Phytother Res. 2008;22(12): 1563-1569.

32. Barnhart CD, Yang D, Lein PJ. Using the Morris water maze to assess spatial learning and memory in weanling mice. PLoS One. 2015;10(4):e0124521.

33. Beheshti S, Ghorbanpour Skakakomi A, Ghaedi K, Dehestani H. Frankincense upregulates the hippocampal calcium/calmodulin kinase II- $\alpha$ during development of the rat brain and improves memory performance. Int J Dev Neurosci. 2018;69:44-48.

34. Beheshti S, Hosseini SA, Noorbakhshnia M, Eivani M. Role of hippocampal CA1 area gap junction channels on morphine state-dependent learning. Eur J Pharmacol. 2014;745:196-200.

35. Biessels GJ, Kamal A, Urban IJ, Spruijt BM, Erkelens DW, Gispen WH. Water maze learning and hippocampal synaptic plasticity in streptozotocin-diabetic rats: effects of insulin treatment. Brain Res. 1998; 800(1):125-135.

36. Ossola B, Kääriäinen TM, Männistö PT. The multiple faces of quercetin in neuroprotection. Expert Opin Drug Saf. 2009;8(4):397-409.
37. Dajas F. Life or death: neuroprotective and anticancer effects of quercetin. J Ethnopharmacol. 2012;143(2):383-396.

38. Lu J, Wu DM, Zheng YL, et al. Quercetin activates AMP-activated protein kinase by reducing $\mathrm{PP} 2 \mathrm{C}$ expression protecting old mouse brain against high cholesterol-induced neurotoxicity. J Pathol. 2010;222(2): 199-212.

39. Jung SH, Murphy EA, McClellan JL, Carmichael MD, Davis JM. The dietary flavonoid quercetin decreases neuroinflammation in a mouse model of Alzheimer's disease. FASEB J. 2010.

40. Rao JS, Kellom M, Kim HW, Rapoport SI, Reese EA. Neuroinflammation and synaptic loss. Neurochem Res. 2012;37(5):903-910.

41. Miao Y, He T, Zhu Y, Li W, Wang B, Zhong Y. Activation of hippocampal CREB by rolipram partially recovers balance between TNF- $\alpha$ and IL-10 levels and improves cognitive deficits in diabetic rats. Cell $\mathrm{Mol}$ Neurobiol. 2015;35(8):1157-1164.

42. Vessal M, Hemmati M, Vasei M. Antidiabetic effects of quercetin in streptozocin-induced diabetic rats. Comp Biochem Physiol C Toxicol Pharmacol. 2003;135C(3):357-364.

43. Srinivasan P, Vijayakumar S, Kothandaraman S, Palani M. Anti-diabetic activity of quercetin extracted from Phyllanthus emblica L. fruit: In silico and in vivo approaches. J Pharm Anal. 2018;8(2):109-118.

44. Yang DK, Kang HS. Anti-Diabetic Effect of Cotreatment with Quercetin and Resveratrol in Streptozotocin-Induced Diabetic Rats. Biomol Ther. 2018;26(2):130-138.

45. Saedi E, Gheini MR, Faiz F, Arami MA. Diabetes mellitus and cognitive impairments. World J Diabetes. 2016;7(17):412.

46. Dajas F, Rivera F, Blasina F, et al. Cell culture protection and in vivo neuroprotective capacity of flavonoids. Neurotox Res. 2003;5(6) 425-432.

47. Bieger J, Cermak R, Blank R, et al. Tissue distribution of quercetin in pigs after long-term dietary supplementation. J Nutr. 2008;138(8): $1417-1420$.

48. Sun C, Lee JS, Zhang M. Magnetic nanoparticles in MR imaging and drug delivery. Adv Drug Deliv Rev. 2008;60(11):1252-1265.

49. Bagad M, Khan ZA. Poly(n-butylcyanoacrylate) nanoparticles for oral delivery of quercetin: preparation, characterization, and pharmacokinetics and biodistribution studies in Wistar rats. Int $J$ Nanomedicine. 2015; 10:3921.

50. Shang L, Nienhaus K, Nienhaus GU. Engineered nanoparticles interacting with cells: size matters. J Nanobiotechnology. 2014;12(1):5.

51. Szalay B, Tátrai E, Nyírö G, Vezér T, Dura G. Potential toxic effects of iron oxide nanoparticles in in vivo and in vitro experiments. $J \mathrm{Appl}$ Toxicol. 2012;32(6):446-453.

52. Alam MM, Abdullah KM, Singh BR, Naqvi AH, Naseem I. Ameliorative effect of quercetin nanorods on diabetic mice: mechanistic and therapeutic strategies. RSC Adv. 2016;6(60):55092-55103.

53. Chitkara D, Nikalaje SK, Mittal A, Chand M, Kumar N. Development of quercetin nanoformulation and in vivo evaluation using streptozotocin induced diabetic rat model. Drug Deliv Transl Res. 2012;2(2):112-123.

54. Mukhopadhyay P, Maity S, Mandal S, Chakraborti AS, Prajapati AK, Kundu PP. Preparation, characterization and in vivo evaluation of $\mathrm{pH}$ sensitive, safe quercetin-succinylated chitosan-alginate coreshell-corona nanoparticle for diabetes treatment. Carbohydr Polym. 2018;182:42-51.

55. Kazemipour N, Nazifi S, Poor MHH, Esmailnezhad Z, Najafabadi RE, Esmaeili A. Hepatotoxicity and nephrotoxicity of quercetin, iron oxide nanoparticles, and quercetin conjugated with nanoparticles in rats. Comp Clin Path. 2018;7(1-2):1-8. 


\section{Publish your work in this journal}

The International Journal of Nanomedicine is an international, peerreviewed journal focusing on the application of nanotechnology in diagnostics, therapeutics, and drug delivery systems throughout the biomedical field. This journal is indexed on PubMed Central, MedLine, CAS, SciSearch $\AA$, Current Contents $\AA /$ Clinical Medicine,
Journal Citation Reports/Science Edition, EMBase, Scopus and the Elsevier Bibliographic databases. The manuscript management system is completely online and includes a very quick and fair peer-review system, which is all easy to use. Visit http://www.dovepress.com/ testimonials.php to read real quotes from published authors.

Submit your manuscript here: http://www.dovepress.com/international-journal-of-nanomedicine-journal 